\title{
Knowledge, Attitude and Perceived Partner and Socio-cultural Support for Family Planning among Women of Reproductive Age in a Rural Community in Ebonyi State, Nigeria
}

Azuogu BN $\mathrm{BN}^{1,2}$, Akamike $\mathrm{IC}^{1}$, Okedo-Alex $\mathrm{IN}^{1}$, Adeke $\mathrm{AS}^{1}$, Agu AP ${ }^{1,2}, \mathrm{Akpa} \mathrm{CO}^{1}$, Obiechina $\mathrm{NC}^{2}$, Akpa WR ${ }^{2}$, Nwali DC ${ }^{2}$, Anyigor $\mathrm{CE}^{2}$

${ }^{1}$ Department of Community Medicine, Alex Ekwueme Federal University Teaching Hospital, Abakaliki, Ebonyi State, Nigeria

${ }^{2}$ Department of Community Medicine, Ebonyi State University, Abakaliki, Ebonyi State, Nigeria

Corresponding author: Akamike Ifeyinwa Chizoba. ifeyakamike@gmail.com, 07068045271. Alex Ekwueme Federal University Teaching Hospital, PMB, 102, Abakaliki, Ebonyi State, Nigeria

\begin{abstract}
Background: Family planning has been adopted as one of the strategies for improving maternal and child health. Family planning is beneficial in reducing maternal and child mortality and therefore, a vital strategy to achieving the Sustainable Development Goals. This study determined the knowledge, attitude, perceived partner and socio-cultural support for family planning among women of reproductive age in Ebonyi State, Nigeria.
\end{abstract}

Methods: A cross-sectional study was conducted among 113 respondents attending antenatal clinic in a Primary health care facility in Nwezenyi village of Izzi Local Government Area. Data collection was in January 2019 over a 4-week period using interviewer-administered questionnaire. Data were analyzed using SPSS version 22 and 95\% confidence interval was used with a p-value of $<0.05$ considered statistically significant. Chi square statistics was used to determine the relationship between sociodemographic characteristics and family planning knowledge. Predictors of family planning knowledge were determined with binary logistic regression using odds ratio as the measure of effect.

Results: More than half of the respondents (65.5\%) had good knowledge while almost all respondents (93.8\%) had good attitude towards family planning. Few of the respondents reported that their doctrine/religion and culture supported family planning (23.9\% and 23\% respectively). Increasing age (AOR: 5.84, 95\%CI: 1.85-18.46) and higher education (AOR: 16.69, 95\%CI: 4.63-60.20) were predictors of family planning knowledge.

\section{Conclusion:}

There was good knowledge and positive attitude towards family planning among respondents, but cultural and doctrinal support of family planning were poor. Higher education and older age were predictors of family planning knowledge.

Keywords: Family planning, Knowledge, Attitude, Socio-cultural Support 


\section{Introduction}

Investing in family planning is a development "best buy" that can accelerate achievements across the five Sustainable Development Goal (SDG) themes of People, Planet, Prosperity, Peace and Partnership.' Family planning assists in reducing maternal and child mortality, and has been one of the most cost-effective investments with far-reaching socioeconomic and environmental advantages for achieving the SDGs. ${ }^{2,3}$

In spite of the enormous benefits of family planning, uptake of the services still remains low in Sub-Saharan Africa. This has resulted in high rates of unwanted pregnancies, unplanned deliveries, unsafe abortions, maternal mortalities and an increase in fertility rate. ${ }^{4}$ The 2018 National Demographic and Health Survey showed that contraceptive prevalence rate for any method of family planning was $17 \%$ among currently married women. Positive attitude of women towards family planning can improve uptake. ${ }^{6}$ Studies have also shown that partner support and socio-cultural characteristics play key roles in influencing use of family planning. ${ }^{79}$ Cultural barriers such as traditional preferences and desires for more children and lineage have been reported to affect uptake of family planning. These beliefs affect the decisions of women and their spouses and negatively impact the implementation of family planning services.

In Ebonyi State, about $70 \%$ of the people live in the rural area where uptake of family planning remains low. ${ }^{5,10}$ Although studies have reported high levels of approval and awareness of family planning, ${ }^{11,12}$ the persistent poor uptake of family planning raises concerns about women's knowledge and attitude regarding family planning as well as the role of partner and socio-cultural support for family planning.

This study set out to determine the knowledge, attitude, perceived partner and socio-cultural support for family planning among women of reproductive age in Ebonyi State, Nigeria.

\section{Methods \\ Study Area and study population}

The study was carried out in a primary health care facility in Nwezenyi village, Izzi Local Government Area (LGA) of Ebonyi North senatorial zone of Ebonyi State. There are 3 senatorial zones in the State: Ebonyi North, Ebonyi South and Ebonyi Central. Izzi is one of the four LGAs in Ebonyi North senatorial zone. The study population consisted of women of reproductive age group (15-49 years) attending antenatal care in the Primary Health Care (PHC) facility. Women of reproductive age who were permanent residents of the study community were included while those who were too ill to participate and those who did not give informed consent were excluded from this study.

\section{Study Design, sample size and sampling technique}

The study used a cross sectional study design. Nwezenyi community was purposively selected for the study because previous studies involving the community had shown a low uptake of family planning services $^{10,12}$ making it necessary to understand further the reasons behind this low uptake in the community. The study facility was purposively selected since it is the major health facility that serves the community. Data collection was carried out over a period of four weeks to avoid spillover of monthly appointments. Sample size was calculated using the formula: $\left(\mathrm{n}=\mathrm{Z}^{2} \mathrm{Pq} \backslash \mathrm{d}^{2}\right)^{13}$ where $\mathrm{n}$ is the minimum sample size, $Z \alpha$ is the standard normal deviate corresponding to a 2 sided level of significance of $5 \%, \mathrm{P}$ is the 
proportion of outcome of interest (knowledge of family planning) from previous study or report taken as $90 \%{ }^{14}$, Q $=1-\mathrm{P}$ and $\mathrm{d}$ is the desired level of precision (usually at $5 \%$ for single proportions).

Applying the formula above,

$$
\begin{aligned}
& \mathrm{n}=\frac{(1.96)^{2} \times 0.90 \times 0.10}{0.05^{2}} \\
& \mathrm{n}=\frac{3.8416 \times 0.90 \times 0.10}{0.0025}=138
\end{aligned}
$$

The finite population correction formula $((\mathrm{N}-\mathrm{n}) /(\mathrm{N}-1))^{1 / 2}$ for population less than 10,000 was applied to the sample size where $\mathrm{N}=$ is the population size, and $\mathrm{n}=$ sample size using an estimated population size of 450 . This gave a value of 115 . An adjustment was then made to the calculated sample size for $10 \%$ nonresponse rate by dividing the originally calculated sample size (n) by 0.9 to give approximately 128 . However, all eligible women who attended antenatal clinic at the selected PHC centre over the four week period and who gave consent were interviewed. A total of 113 women participated in this study giving a response rate of $89 \%$.

\section{Data Collection}

Information was collected on knowledge, attitude and support for family planning using an interviewer administered questionnaire adapted from previous studies. ${ }^{12,14,15}$ Pre-testing of questionnaire was done among women in a community different from the study community. The questionnaire was divided into four sections. The first section collected information on the socio-demographic characteristics of the respondents; the second section explored general knowledge on the types and functions of family planning methods. The third section collected data on attitude towards family planning while the last section assessed partner decision making for family planning and perceived cultural and religious support for family planning. Data collection was carried out over a four week period in January, 2019 by trained research assistants. The training of the research assistants ensured that the research assistants understood the questions and these questions were also explained to them in the local dialect which was the dialect used for administering the questionnaires.

\section{Data management and analysis}

The data was analyzed using Statistical Package for Social Sciences (SPSS), software package version 20. The independent variables were the sociodemographic characteristics of the respondents such as age, marital status, level of education, religion and employment status. Frequencies and proportions were calculated for categorical variables while the means and standard deviations were calculated for numeric/quantitative variables.

The primary outcome variable was knowledge while attitude and support for family planning were the secondary variables. Five questions were used to assess knowledge of family planning and a score of " 1 " was given for a correct answer and " 0 " for a wrong answer. However, one of the questions had 7 multiple choice options and so was scored "1" for each option. Total score possible varied from 0 11 and was classified into two levels (Good knowledge: 6-11, and poor knowledge 0-5 scores). Six 5-point Likert scale questions were used to assess attitude towards family planning. Mean Neutral Rating (MNR) of these Likert scale responses was done and attitude was classified as positive at mean values between 3.00-5.00 and negative at mean values less than 3.00. Support for family planning was assessed using four questions that asked about partner decision making, cultural and religious support for family planning. Affirmative responses to three of these questions was taken as 
support while negative response to the fourth question was taken as support. Descriptive statistics were used to summarize the data in relation to the different variables. The Chi square statistic was used to determine the relationship between socio-demographic characteristics and knowledge of family planning at 5\% level of significance. Multiple logistic regression analysis was carried out to determine predictors of family planning knowledge. The cut-off point for including variables into the regression model was $p=0.1$ after cross tabulation. This cut-off point was used based on recommendation in a previous statistical publication. $^{16}$

\section{Ethics approval and consent to participate}

Ethical clearance for this study was obtained from Research and Ethics Committee of Alex Ekwueme Federal University Teaching Hospital, Abakaliki, Nigeria. Only those women who agreed by signing the informed consent form participated in the study. Although the study population included women of reproductive age (15-49years) attending antenatal care, those who were less than 16 years were not encountered in the course of sampling.

\section{Results}

Table 1 shows that more than half of the respondents $(58.4 \%)$ were 30 years or less. Majority $(80.5 \%)$ were married while most $(78.8 \%)$ had at least secondary education. Majority of the participants were employed. Table 2 shows that majority of the respondents $(70.8 \%)$ had heard of family planning. The natural method of family planning was the most known method $(88.5 \%)$. Majority $(89.4 \%)$ of the respondents knew that family planning prevents unwanted pregnancy, limits family size (85.5) and helps with child spacing $(86.7 \%)$. Majority of the respondents $(65.5 \%)$ had overall good knowledge (Table 2). Table 3 shows the perceived religious and cultural support for family planning. Low proportions of the respondents reported that their culture $(23 \%)$ and religion $(23.9 \%)$ supported family planning. Also for over half of the respondents $(66.4 \%)$, their partners were aware of family planning. Only few of the respondents reported that their partners decided on the family size all alone. Table 4 shows that overall attitude of respondents towards family planning was positive (93.8\%). Majority of the respondents believed that family planning is very safe. A good number strongly approved of family planning while about $60 \%$ affirmed that family planning has benefits. Most of the respondents strongly disagreed with the idea that family planning is harmful or causes barrenness. Table 5 shows that predictors of knowledge were age and educational status of mothers. Those aged 30 years and above were 5.8 times more likely to have good knowledge of family planning compared to those that were younger (AOR: 5.84, 95\%CI: 1.85-18.46). Those that had secondary education or more were also more likely to have better knowledge of family planning compared to those with lower education (AOR: 16.69, 95\%CI: 4.63-60.20). 
Table 1: Socio-demographic characteristics of respondents

\begin{tabular}{lll}
\hline Variable & $\begin{array}{l}\text { Frequency } \\
\mathrm{n}=113\end{array}$ & $\begin{array}{l}\text { Percentage } \\
(\%)\end{array}$ \\
Age (years) & 66 & 58.4 \\
$\leq 30$ & 47 & 41.6 \\
$>30$ & $30.63 \pm 6.27$ & \\
Mean age $\pm \mathrm{SD}$ & & \\
Marital Status & 91 & 80.5 \\
Married & 22 & 19.5 \\
Others* & & \\
Religion & 105 & 92.9 \\
Christianity & 8 & 7.1 \\
Islam & & \\
Education & 24 & 21.2 \\
Primary & 89 & 78.8 \\
Secondary & & \\
Employment status & 20 & 17.7 \\
Unemployed & 93 & 82.3 \\
Employed & & \\
\hline
\end{tabular}


Table 2: Knowledge of family planning methods among women

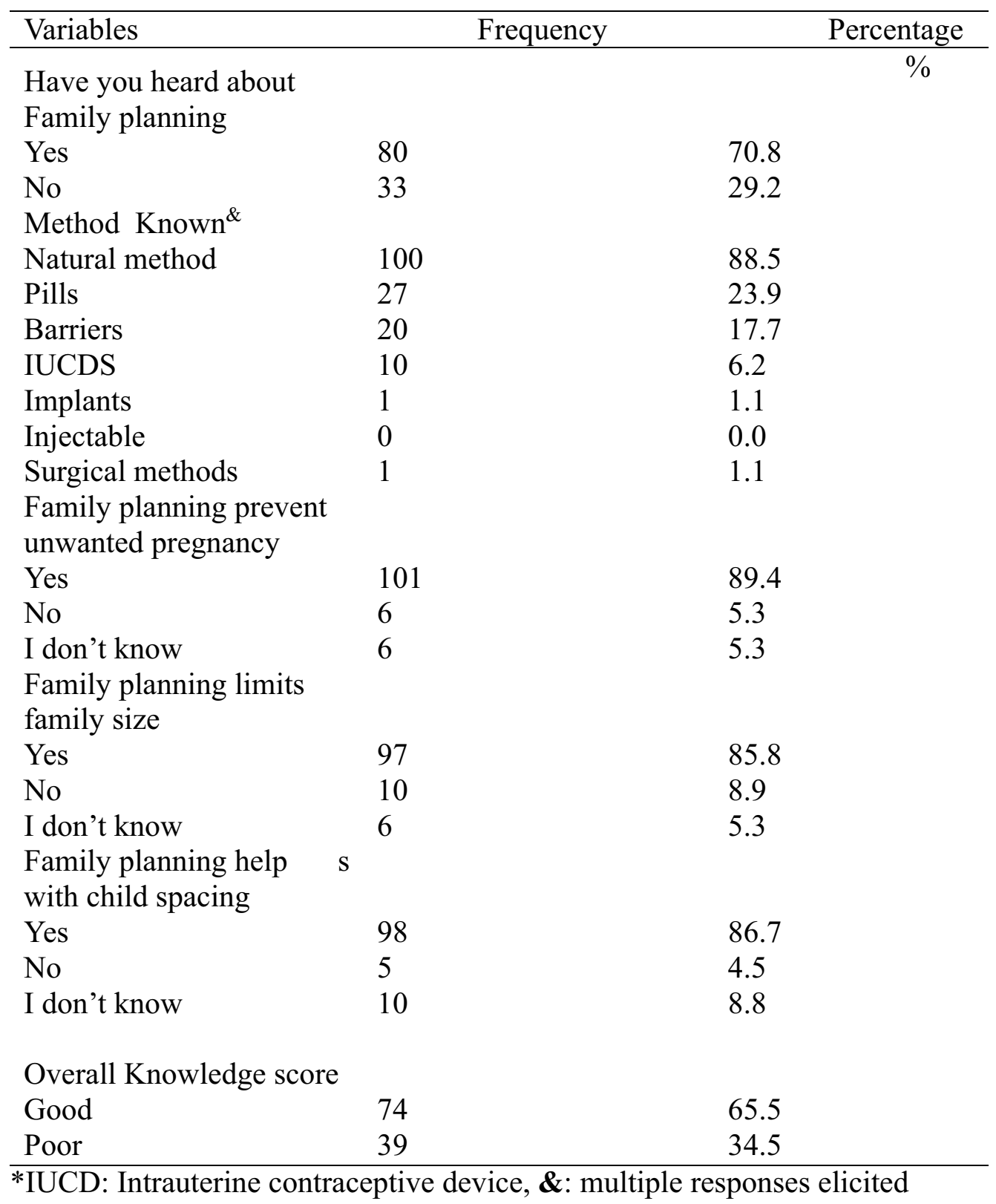


Table 3: Perceived religious, cultural and partner support for family planning

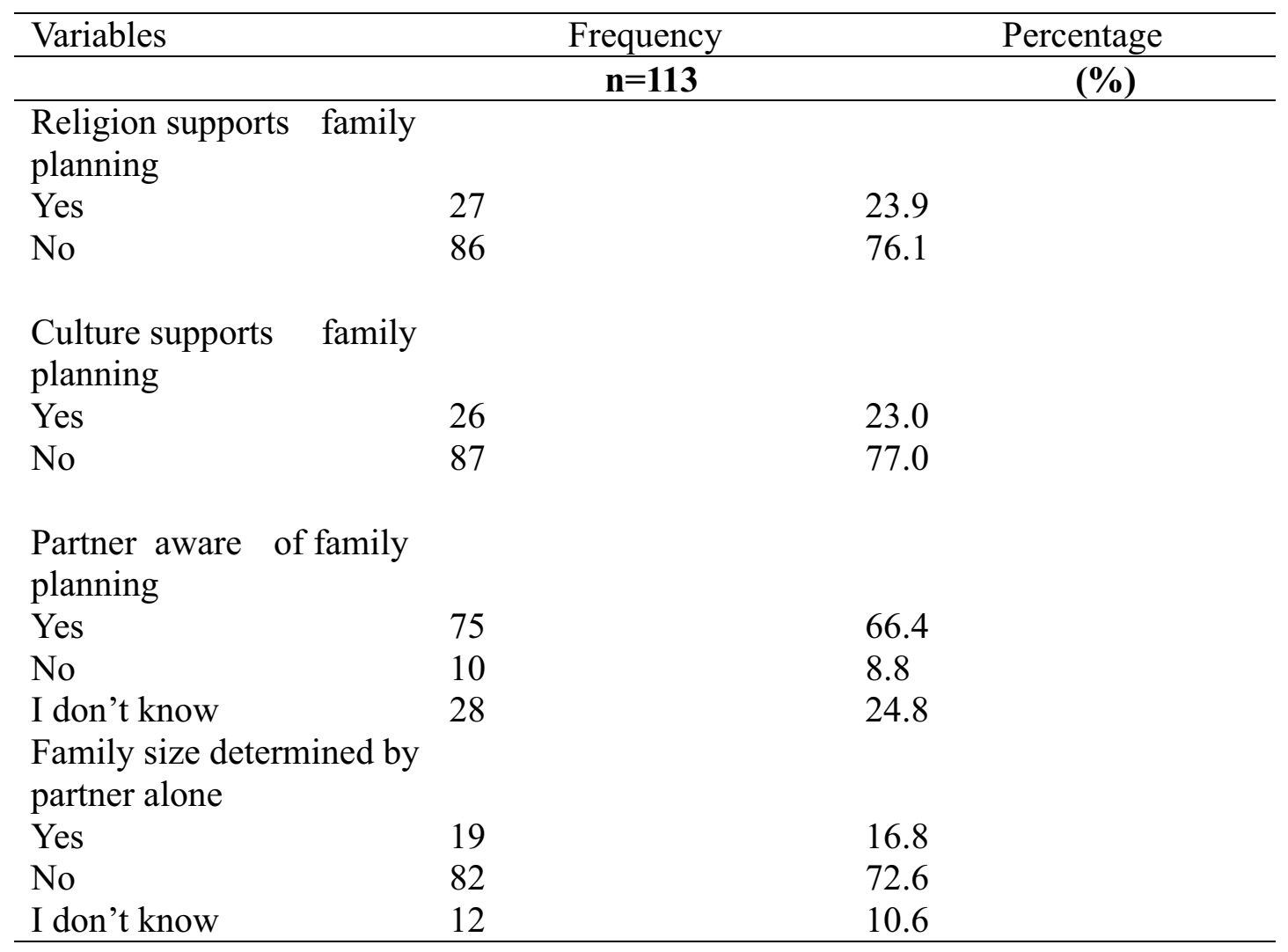


Table 4: Respondent's attitude towards family planning

\begin{tabular}{|c|c|c|}
\hline Variables & Frequency & Percentage \\
\hline & $\mathrm{n}=113$ & $\%$ \\
\hline \multicolumn{3}{|c|}{$\begin{array}{l}\text { Rating of safety of family } \\
\text { planning }\end{array}$} \\
\hline Not safe & 4 & 3.5 \\
\hline Partially safe & 7 & 6.2 \\
\hline Indifferent & 12 & 6.2 \\
\hline Safe & 7 & 10.6 \\
\hline Very safe & 83 & 73.5 \\
\hline \multicolumn{3}{|l|}{$\begin{array}{l}\text { Approval of family } \\
\text { planning }\end{array}$} \\
\hline Strongly disapprove & 26 & 23.0 \\
\hline Disapprove & 1 & 0.9 \\
\hline Indifferent & 17 & 15.0 \\
\hline Strongly approve & 69 & 61.1 \\
\hline \multicolumn{3}{|l|}{$\begin{array}{l}\text { Family planning has } \\
\text { benefits }\end{array}$} \\
\hline Strongly disagree & 30 & 26.5 \\
\hline Disagree & 2 & 1.8 \\
\hline Indifferent & 10 & 8.8 \\
\hline Agree & 23 & 20.4 \\
\hline Strongly agree & 48 & 42.5 \\
\hline \multicolumn{3}{|c|}{ Family planning is harmful } \\
\hline Strongly disagree & 71 & 62.8 \\
\hline Disagree & 15 & 13.3 \\
\hline Indifferent & 9 & 8.0 \\
\hline Agree & 9 & 8.0 \\
\hline Strongly agree & 9 & 8.0 \\
\hline $\begin{array}{l}\text { Family planning cause } \\
\text { barrenness }\end{array}$ & & \\
\hline Strongly disagree & 78 & 69.0 \\
\hline Disagree & 11 & 9.7 \\
\hline Indifferent & 14 & 12.4 \\
\hline Agree & 9 & 8.0 \\
\hline Strongly agree & 1 & 0.9 \\
\hline \multicolumn{3}{|c|}{ Only natural method is safe } \\
\hline Strongly disagree & 75 & 66.4 \\
\hline Disagree & 7 & 6.2 \\
\hline Indifferent & 16 & 14.2 \\
\hline Agree & 13 & 11.5 \\
\hline \multicolumn{3}{|l|}{ Overall Attitude Score } \\
\hline Positive & 106 & 93.8 \\
\hline Negative & 7 & 6.2 \\
\hline
\end{tabular}


Table 5: Predictors of knowledge of family planning

\begin{tabular}{lllll}
\hline Predictors of Knowledge & AOR & $95 \%$ CI & P value \\
\hline Age & $\begin{array}{l}>30 \text { years } \\
\leq 30 \text { years }\end{array}$ & 5.84 & $1.85-18.46$ & 0.003 \\
Marital Status & 1 & & \\
& $\begin{array}{l}\text { Married } \\
\text { Others* }\end{array}$ & 0.71 & $0.21-2.41$ & 0.577 \\
$\begin{array}{l}\text { Educational } \\
\text { Status }\end{array}$ & 1 & & \\
& $\begin{array}{l}\text { Secondary or more } \\
\text { Primary and less }\end{array}$ & $\begin{array}{l}16.69 \\
1\end{array}$ & $4.63-60.20$ & 0.00 \\
\hline
\end{tabular}

*single, divorced

\section{Discussion}

Majority of the respondents were aware of family planning and the most commonly known method was the natural method followed by the pills and barrier methods. This high awareness is similar to what was found in previous studies. ${ }^{7,1720}$ This result could be explained by the fact that majority of the respondents had received education on family planning at one time or the other. In addition, the respondents were interviewed at the antenatal clinic and so there is a possibility that they received counseling during these visits. This study also found that majority of the women knew the benefits of family planning. Knowledge of benefits of a particular health behavior is crucial in influencing practice. According to the health belief model of behavior change, potential positive benefits of action or perceived benefits is one of the key factors that influence health behaviors. ${ }^{21}$

This study further revealed that the women had a positive attitude towards family planning. Majority of the respondents admitted that family planning was very safe and also approved of family planning while a good number strongly disagreed with the idea that family planning is harmful or that it caused infertility. This is similar to a study carried out in Ebonyi
State, Nigeria which showed that $69.4 \%$ of respondents approved of family planning. ${ }^{22}$

This similarity is not surprising since the two studies were carried out in same region.

A good number of women in this study reported that their spouses/partners were aware of family planning. Approval of family planning by spouses plays a pivotal role in use of family planning methods, therefore, increasing awareness among the men is a first step in getting husbands to approve of family planning. Husband's/partner's support for family planning may influence a woman's modern contraceptive use. ${ }^{23}$ Only few of the respondents reported that their religion or culture supported family planning. A study carried out in Tanzania revealed that a number of participants saw family planning as fundamentally opposed by their religious beliefs frequently referring to the scriptural verse that says we should multiply and fill the land. ${ }^{15}$ Some doctrines prohibit the use of contraceptives with the argument that the primary purpose of marriage is procreation. ${ }^{24}$ Furthermore, the decisions of most Nigerians are based on their beliefs including religious beliefs since these beliefs make up a part of their day to day lives. ${ }^{25,26}$ Therefore, interventions for shaping norms and informing behaviors about family 
planning and contraceptive use through engaging religious leaders as advocates of family planning may have some impact.27 Studies have shown that interventions that are religion-based improved uptake of family planning. In Kenya, a study that aimed to enhance voluntary family planning performance at Faith Based Organisation-managed health facilities by mobilizing community health volunteers and religious leaders reported a rapid and sustained increase in family planning uptake. ${ }^{28}$ Cultural beliefs that prevent women from making their own decisions can impact the implementation of family planning services negatively. A systematic review of barriers to contraceptive use in sub-Saharan Africa found that cultural and societal pressure on women constrained uptake of contraceptive services. ${ }^{29}$ Innovative approaches that are different from those implemented for other health care services are required to overcome these barriers.

Older women were more likely to have knowledge about family planning. This can be explained by the fact that older age may be associated with more experience and older women may have received more counseling as a result of their previous deliveries and antenatal visits. Higher educational status was also found to be a predictor of family planning knowledge. Previous studies have reported that lower education is a barrier to use of family planning. ${ }^{3033}$ Family planning counseling should target women with lower education and such counseling and education should consider the context of these women and ensure that family planning messages are simplified for better understanding.

In general, our findings show that efforts being made to improve uptake of family planning have yielded some benefits as reflected by the good knowledge and positive attitude of the respondents and also the high awareness levels among their spouses. However, only a few of the respondents were certain about their religious or culture support for family planning. Therefore efforts towards improving uptake of family planning should explore the religious and cultural barriers with the aim of identifying context specific strategies that will improve support of family planning, thereby improving uptake. This study was carried out among women attending antenatal care clinic in only one health facility, this could therefore limit the extent to which the findings can be generalized. Another limitation of this study is the small sample size.

\section{Conclusion}

There was good knowledge and positive attitude towards family planning among respondents. Few respondents reported cultural and doctrinal support of family planning and lower education and age were predictors of family planning knowledge. Further studies to identify strategies that target the cultural and religious barriers to family planning are recommended. There is need for increased sensitization to improve knowledge of methods of family planning ensuring that both the educated and less educated are captured in awareness programs.

\section{Competing interests}

The authors declare that they have no competing interests.

Funding

None

\section{Authors' contributions}

ABN, AIC OIN and AAP worked on study conceptualization and design. ONC, AWD, NDC and ACE led efforts for data collection activities. AIC, ABN, OIN, and ONC conducted data analysis and interpretation. The first draft of the manuscript was written and prepared by AIC, AAS, ONC, AWD, NDC and ACO. 
All authors significantly contributed to and approved of the final version

\section{REFERENCES}

1. Starbird E, Norton M. Investing in Family Planning: Key to Achieving the Sustainable Development Goals health. Glob Heal Sci Pract. 2020;120.

2. Health policy Plus. Family PlanningSustainable Development Goals (FP$\mathrm{S} D \mathrm{D} \mathrm{s}$ ) $\quad \mathrm{M}$ o d e 1.20019 . http://www.healthpolicyplus.com/fpSDGs .cfm. Accessed April 2020

3. Jurczynska K, Sacher S, Moreland S. Family Planning Can Mean Big Progress for the Sustainable Development GoalsAnd Heres How. New Security Beat. 2018;

https://www.newsecuritybeat.org/2018/07

/family-planning-big-progresssustainable-development-goals-andheres/. Accessed April 2020

4. Africa Progress Panel. Maternal Health: Investing in the Lifeline of Healthy Societies \& Economics. 2010. https://reliefweb.int/report/world/maternal -health-investing-lifeline-healthysocieties-and-economies. Accessed April 2020

5. National Population Commission. Nigerian Demographic And Health Survey 2018.

6. Obwoya JG, Wulifan JK, Kalolo A. Factors Influencing Contraceptives Use among Women in the Juba City of South Sudan. $\begin{array}{lcccc}2 & 0 & 1 & 8 & \\ \text { https://doi.org/10.1155/2018/6381842http }\end{array}$ s://www.hindawi.com/journals/ijpr/2018/ 6381842/. Accessed march 2020

7. Ezeanolue EE, Iwelunmor J, Asaolu I, Obiefune MC, Ezeanolue CO, Osuji A, et al. Impact of male partners awareness and support for contraceptives on female intent to use contraceptives in southeast Nigeria. BMC Public Health. 2015;15(1):879.

8. Kriel Y, Milford C, Cordero J, Suleman F, Beksinska M, Steyn P, et al. Male partner influence on family planning and contraceptive use: perspectives from community members and healthcare providers in KwaZulu-Natal, South
Africa. Reprod Health. 2019;16(89):115.

9. Kabagenyi A, Reid A, Ntozi J, Atuyambe L. Socio-cultural inhibitors to use of modern contraceptive techniques in rural Uganda: a qualitative study Allen. Pan Afr Med J. 2016;25:78.doi:10.11604/pamj.2016.25.7 8.6613

10. Akamike IC, Mbachu C, Onwasigwe C, Okedo-Alex I, Eze I, Eze N. Role of community resource persons in improving use of modern family planning methods among women of reproductive age in a rural area in Ebonyi State, Nigeria. Int J Health Plann Manage. 2019; 34(1). doi:10.1002/hpm.2746

11. Ikechebelu JI, Joe-Ikechebelu NN, Obiajulu FN. Knowledge, attitude and practice of family planning among Igbo women of south-eastern Nigeria. J Obstet Gynaecol. 2005;25(8):7925.

12. Akamike IC, Okedo-Alex IN, Madubueze UC, Umeokonkwo CD. Does community mobilisation improve awareness, approval and uptake of family planning methods among women of reproductive age in Ebonyi State? Experience from a quasiexperimental study. Pan Afr Med J. 2019;33:19.

13. Lwanga SK, Lemeshow S, World Health Organisation. Sample size determination in health studies: a practical manual / S. K. Lwanga and S. Lemeshow. World Health O r g a n i z a t i o n. 1991 . . https://apps.who.int/iris/handle/10665/400 62. Accessed April 2020

14. Omolase CO, Faturoti SO, Omolase BO. Awareness of family planning amongst antenatal patients in a nigerian community: an exploratory study. Ann Ibadan Postgrad Med. 2009;7(1):369.

15. Sundararajan R, Yoder LM, Kihunrwa A, Aristide C, Kalluvya SE, Downs DJ, et al. How gender and religion impact uptake of family planning: results from a qualitative study in Northwestern Tanzania. BMC Womens Health. 2019;19:110.

16. Maldonado G, Greenland S. Simulation Study of Confounder-Selection Strategies. Am J Epidemiol. 1993;138(11):92336.

17. Aryeetey R, Kotoh AM, Hindin MJ. Knowledge, perceptions and ever use of 
modern contraception among women in the Ga East District, Ghana. Afr J Reprod Health. 2010;14(4 Spec no.):2631.

18. Fusi-Ngwa C, Payne V, Asakizi A, Katte B. Knowledge and Practice of Family Planning in Dschang Municipality, Cameroon. African Journal of Reproductive Health. 2013:13748.

19. Ochako R, Mbondo M, Aloo S, Kaimenyi $\mathrm{S}$, Thompson $\mathrm{R}$, Temmerman $\mathrm{M}$, et al. Barriers to modern contraceptive methods uptake among young women in Kenya: a qualitative study. BMC Public Health. 2015;15(1):118.

20. Teye JK. Modern contraceptive use among women in the Asuogyaman district of Ghana: is reliability more important than health concerns? Afr J Reprod Health. 2013;17(2):5871.

21. Rural Health Information Hub. The Health $\mathrm{B}$ e $1 \mathrm{i}$ e f $\mathrm{M}$ o d e 1.2020 . https://www.ruralhealthinfo.org/toolkits/h ealth-promotion $/ 2 /$ theories-andmodels/health-belief

22. Egede JO, Onoh RC, Umeora OUJ, Iyoke CA, Dimejesi IBO, Lawani LO. Contraceptive prevalence and preference in a cohort of south-east Nigerian women. Patient Prefer Adherence. 2015;9:70714.

23. Prata N, Bell S, Fraser A, Carvalho A, Neves I, Nieto-Andrade B. Partner Support for Family Planning and Modern Contraceptive Use in Luanda, Angola. Afr J Reprod Heal. 2017;21(2):3548.

24. Schenker JG, Rabenou V. Contraception: traditional and religious attitudes. Eur $\mathrm{J}$ Obstet Gynecol Reprod Biol. 1993;49(1993):158.

25. Adedini SA, Odimegwu C, Imasiku ENS. Ethnic differentials in under-five mortality i n $\mathrm{Nigeria}$. E th n $\mathrm{Hea} 1 \mathrm{th}$. 2015;20(2):14562.

26. Oguntola-laguda D. Religion, Leadership and struggle for power in Nigeria: A case study of the 2011 presidential election in
Nigeria. Stud Hist Eccles. 2015;41(2):21933.

27. Adedini SA, Babalola S, Ibeawuchi C, Omotoso O, Akiode A, Odeku M. Role of Religious Leaders in Promoting Contraceptive Use in Nigeria: Evidence From the Nigerian Urban Reproductive Health Initiative. Glob Heal Sci Pract. 2018;6(3):50014.

28. Ruark A, Kishoyian J, Bormet M. Increasing Family Planning Access in Kenya Through Engagement of FaithBased Health Facilities, Religious Leaders, and Community Health Volunteers. 2019;7(3):47890.

29. Haider TL, Sharma M. Barriers to family planning and contraception uptake in subSaharan Africa: a systematic review. Int Q Com munity $\mathrm{Health} \mathrm{Educ}$. 2012;33(4):40313.

30. Adebayo AM, Ojo TO, Omotoso BA, Ayodeji OO. Family planning services in a tertiary hospital in a semi-urban area of south-western Nigeria: Uptake and determinants of contraceptive use. J Obstet Gynaecol(Lahore). 2016;36(7):9048.

31. Adebowale SA, Fagbamigbe FA, Bamgboye EA. Contraceptive use: implication for completed fertility, parity progression and maternal nutritional status in Nigeria. Afr J Reprod Health. 2011;15(4):607.

32. Adeyemi A, Olugbenga-Bello AI, Adeoye O, Salawu M, Aderinoye A, Agbaje M. Contraceptive prevalence and determinants among women of reproductive age group in Ogbomoso, Oyo State, Nigeria. Open Access J Contracept. 2016;7:3341.

33. Solanke BL. Factors influencing contraceptive use and non-use among women of advanced reproductive age in Nigeria. J Heal Popul Nutr . 2017;114. http://dx.doi.org/10.1186/s41043-0160077-6. Accessed August 2017 